\title{
How to Improve Effectiveness and Adherence to Antihypertensive Drug Therapy: Central Role of Dihydropyridinic Calcium Channel Blockers in Hypertension
}

\author{
Giuliano Tocci ${ }^{1,2}$ (D) Giovambattista Desideri $^{3} \cdot$ Elisa Roca $^{4} \cdot$ Calogero Calcullo $^{5} \cdot$

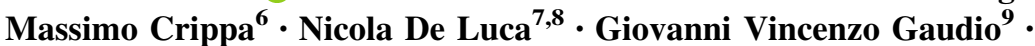 \\ Laura Maria Lonati ${ }^{10}$ - Leo Orselli ${ }^{11}$ - Angelo Scuteri ${ }^{12}$ - Vito Vulpis ${ }^{13}$. \\ Benedetto Acone $^{14}$ - Augusto Zaninelli ${ }^{15}$ on behalf of the THYPERevolution Steering \\ Committee
}

Received: 11 September 2017 / Accepted: 20 November 2017/Published online: 2 December 2017

(C) The Author(s) 2017. This article is an open access publication

\begin{abstract}
Essential hypertension is a complex clinical condition, characterized by multiple and concomitant abnormal activation of different regulatory and contraregulatory pathophysiological mechanisms, leading to sustained increase of blood pressure (BP) levels. Asymptomatic rise of BP may, indeed, promote development and progression of hypertension-related organ damage, which in turn, increases the risk of major cardiovascular and cerebrovascular events. A progressive and independent relationship has been demonstrated between high BP levels and increased cardiovascular risk, even in the high-tonormal range. Conversely, evidence from randomized controlled clinical trials have independently shown that lowering BP to the recommended targets reduces individual cardiovascular risk, thus improving event-free survival and reducing the incidence of hypertension-related cardiovascular events. Despite these benefits, overall rates of
\end{abstract}

Giuliano Tocci

giuliano.tocci@uniroma1.it

1 Division of Cardiology, Department of Clinical and Molecular Medicine, Faculty of Medicine and Psychology, Sant'Andrea Hospital, University of Rome Sapienza, Rome, Italy

2 IRCCS Neuromed, Pozzilli, IS, Italy

3 MeSVA Department, Chair and School of Geriatric Medicine,Civil Hospital of Avezzano, Division of Geriatric Medicine, University of L'Aquila, Coppito, Italy

4 Department of Molecular and Translational Medicine, University of Brescia, Brescia, Italy

5 ASL Agrigento, Agrigento, Italy

6 Ospedale di Gardone Val Trompia, Brescia, Italy

7 Hypertension Research Center, Federico II University, Naples, Italy
BP control remain poor, worldwide. Currently available guidelines support a substantial equivalence amongst various antihypertensive drug classes. However, several studies have also reported clinically relevant differences among antihypertensive drugs, in terms of both BP lowering efficacy and tolerability/safety profile. These differences should be taken into account not only when adopting first-line antihypertensive therapy, but also when titrating or modulating combination therapies, with the aim of achieving effective and sustained BP control. This review will briefly describe evidence supporting the use of dihydropyridinic calcium channel blockers for the clinical management of hypertension, with a particular focus on barnidipine. Indeed, this drug has been demonstrated to be effective, safe and well tolerated in lowering BP levels and in reducing hypertension-related organ damage, thus

8 Department of Translational Medical Sciences, Federico II University, Naples, Italy

9 Ospedale di Somma Lombardo, Varese, Italy

10 Università di Milano, Milan, Italy

11 ASL Bologna, Bologna, Italy

12 Department of Medicine, UOC Hypertension and Nephrology, Policlinico Tor Vergata, Rome, Italy

13 Department of Neurological and Psychiatric Sciences, Neurophysiopathology, Hypertension, Medical School of Bari, University of Bari, Bari, Italy

14 Istituto "Cartesio" di Venezia, Venezia, Italy

15 School of Medicine, University of Florence, Florence, Italy 
showing a potential key role for improving the clinical management of hypertension.

Keywords Antihypertensive therapy - Barnidipine . Combination therapy $\cdot$ Dihydropyridinic calcium channel blockers $\cdot$ Hypertension $\cdot$ Monotherapy

\section{Introduction}

Essential hypertension is the major modifiable cardiovascular (CV) risk factor associated with an increased risk of developing coronary artery disease, myocardial infarction, stroke, congestive heart failure, and CV death. Indeed, high blood pressure (BP) levels have been independently correlated with an increased susceptibility to metabolic abnormalities and renal impairment, ranging from microalbuminuria to end-stage renal disease. Increased CV risk related to hypertension is independent of age, gender, ethnicity, and the presence of concomitant CV risk factors or comorbidities. Conversely, lowering BP levels to the recommended targets (i.e. below 140/90 $\mathrm{mmHg}$ ) has been demonstrated to provide beneficial effects in terms of a reduced incidence of $\mathrm{CV}$ outcomes and improved eventfree survival rates.

Despite the availability of numerous effective and welltolerated antihypertensive drug therapies, and beyond the implementation of favourable life-style changes, epidemiological and clinical studies have consistently and repeatedly shown poor rates of BP control in various European and Western countries [1-3], including Italy [4, 5]. More recently, systematic assessment of hypertension management and control have also reported relatively low rates of awareness, treatment, and control in Asia-Pacific countries, thus highlighting the epidemic proportion of the socalled "hypertension paradox", which is characterized by the high prevalence and low control rate of the disease, worldwide [6].

Several strategies have been proposed by scientific societies for improving BP management and control, mostly through implementing international guideline recommendations for the proper selection of antihypertensive drug therapy according to individual global $\mathrm{CV}$ risk profile $[7,8]$. Among possible pharmacological therapies currently available for the clinical management of hypertension, antihypertensive therapy based on the use of dihydropyridinic calcium channel blockers (CCB) has been demonstrated to be effective, safe and well tolerated in lowering BP levels and in reducing hypertension-related organ damage $[9,10]$.

In 2016 an educational program was performed in Italy with the aims of ameliorating the clinical management of hypertension and improving BP control rates by adopting rational, effective and well-tolerated antihypertensive drug therapies. This program, entitled THYPERevolution, was designed for different professional figures involved in the clinical management of hypertension. Following the analysis of the recently available clinical evidence discussed during these meetings, this review will briefly examine the potential role of antihypertensive therapy based on the use of CCBs for the clinical management of hypertension, with a particular focus on barnidipine.

\section{Pharmacological Considerations on Calcium Channel Blockers}

There are a number of important differences between therapeutic agents within the drug class of CCBs from a pharmacokinetic [11] and pharmacodynamic [12] point of view, and in their selectivity and duration of pharmacological action [13-15], which exist despite their ability to interact with L-type voltage-dependent transmembrane calcium channels. Unsurprisingly, the clinical and therapeutic effectiveness of CCBs in different clinical settings is affected as a result of these differences, along with their tolerability and safety profiles.

In order to distinguish different compounds within the drug class of CCBs, a number of classifications have been proposed. In one such classification, CCBs are separated into three groups based on their selectivity for interactions with either cardiac or vascular (or both) L-type voltagedependent transmembrane calcium channels [16, 17]. This classification stratifies CCBs into three groups: (1) dihydropyridinic agents, which mostly act as dilating agents at the peripheral vessel level; (2) phenilalchilaminic agents, which predominantly act as negative inotropes and chronotropes at the cardiac level; and, (3) benzothiazepinic agents, which show an intermediate profile.

Nifedipine, verapamil, and diltiazem, respectively, were the first generation compounds of these three groups. However, their short acting therapeutic action has restricted their clinical effectiveness due to the possibility of drugrelated adverse reactions (e.g. peripheral oedema, reflex tachycardia, and skin reactions). In more recent years, new slow-release formulations of "old" CCBs have been proposed and widely used in clinical practice, with a significant reduction of side effects observed with the same drugs when administered as short-acting formulation. Consequently, second and third generation CCBs were developed and have been used extensively for the treatment of hypertension and $\mathrm{CV}$ diseases. Amongst the group of dihydropyridinic agents, second and third generation CCBs including manidipine [18, 19], felodipine [20, 21], and nicardipine [22], and lacidipine [23], lercanidipine [24], barnidipine [25], and amlodipine [26], respectively, show 
improved selectivity for vascular calcium channels and more favourable pharmacokinetic and pharmacodynamic profiles compared with nifedipine.

Among these drugs, barnidipine, in a special preparation of a mixture of slow- and quick-releasing particles, is a long-acting dihydropyridinic CCB. The slow-releasing particles are coated with a membrane that can delay the release of barnidipine. With once-daily administration, barnidipine has shown potent antihypertensive action [27]. The modified-release, single-isomer formulation of barnidipine provides a slow onset of action combined with a sustained delivery of drug to effectively control BP throughout a 24-h period without causing hypotension or reflex tachycardia [27], and some additional benefits in reducing central blood pressure, possibly explaining the improvement in diastolic function [28]. Finally, its long duration of action, due to its lipophilicity, means that satisfactory BP control can be obtained with once-daily dosing [25].

\section{Calcium-channel Blockers and Current Indications for Hypertension Treatment}

Recognised evidence showing equivalence in terms of antihypertensive efficacy and in risk reduction of major CV events amongst the five antihypertensive drug classes (angiotensin converting enzyme (ACE) inhibitors, angiotensin receptor blockers (ARBs), beta-blockers, CCBs, and diuretics), provides physicians with a selection of therapeutic agents for the first-choice and maintenance antihypertensive treatment in monotherapy [29]. However, despite substantial equivalence in terms of antihypertensive effectiveness for these different antihypertensive drug classes, there are relevant differences regarding their indications and contraindications [29], which may limit their usefulness. In addition, several studies have demonstrated better tolerability profiles $[30,31]$ and more favourable metabolic properties [32-34] for drugs which inhibit the renin-angiotensin system (RAS) (i.e. ACE inhibitors or ARBs) and for CCBs compared with betablockers and diuretics.

CCB-based monotherapy offers an effective and safe means to control hypertension in patients with grade 1 hypertension, particularly for patients with compelling indications [29]. Current European guidelines recommend dihydropyridinic $\mathrm{CCBs}$ for lowering BP levels in black individuals, elderly subjects with isolated systolic hypertension, as well as in hypertensive patients with metabolic syndrome, cardiac (left ventricular hypertrophy) or vascular (atherosclerosis) organ damage, previous stroke or peripheral artery disease [29]. Indeed, for the treatment of hypertension and to reduce hypertension-related CV morbidity and mortality, dihydropyridinic CCBs are considered as one of the first-line therapeutic options [29]. Moreover, sustained antihypertensive efficacy and reduced $\mathrm{CV}$ and renal complications have been demonstrated for $\mathrm{CCBs}$ as monotherapy compared with other antihypertensive drug classes in several clinical settings, including high risk patients with hypertension, coronary artery disease, stroke, and renal failure [35-41].

It should also be noted that combination therapy based on a minimum of two drug classes may be needed to attain recommended BP targets for the vast majority of hypertensive patients [42]. For hypertensive patients with unsatisfactory BP control under monotherapy, or those with high or very high $\mathrm{CV}$ risk profiles, a combination of two antihypertensive classes, including CCBs, can be used.

\section{Calcium-channel Blockers, Hypertension and High Cardiovascular Risk}

The efficacy, safety and tolerability of CCB-based antihypertensive treatment has been assessed in hypertensive patients with high or very high $\mathrm{CV}$ risk in a number of international, randomized controlled clinical trials [35-41]. These trials have consistently confirmed the superior efficacy of CCBs in reducing both BP levels and the incidence of major $\mathrm{CV}$ events compared with either diuretics or betablockers, as well as equivalence to RAS blocking agents [35-41]. In addition, several randomized, controlled clinical trials have also assessed the efficacy, safety and tolerability of CCBs in adult hypertensive patients with additional risk factors [43-46].

The addition of low-dose felodipine to low-dose hydrochlorothiazide decreased systolic BP/diastolic BP on average by $4.2 / 2.1 \mathrm{mmHg}$ compared with placebo in the Felodipine Event Reduction (FEVER) trial, which enrolled 9800 Chinese patients (aged 50-79 years) with hypertension plus one or two additional CV risk factors or disease [46]. Although this difference was small, it was associated with significant reductions in most $\mathrm{CV}$ events including a $27 \%$ reduction in the primary endpoint (fatal and non-fatal stroke) in the felodipine group ( $\mathrm{p}=0.001$ versus placebo). Among secondary endpoints, significant reductions in all CV events (by 27\%; p < 0.001), all cardiac events (by 35\%; $\mathrm{p}=0.012$ ), death by any cause (by $31 \% ; \mathrm{p}=0.006$ ), coronary events (by 32\%; $\mathrm{p}=0.024$ ), and CV death (by $33 \% ; \mathrm{p}=0.019)$ were shown for felodipine versus the control group.

A chlorthalidone-based regimen was shown to lower BP levels more than CCBs or ACE inhibitors in the Antihypertensive and Lipid-Lowering Treatment to Prevent Heart Attack Trial (ALLHAT) [43]. In this double-blind, activecontrolled, randomized clinical trial, 33,357 patients, aged 
55 years or older, with a history of hypertension and at least one additional $\mathrm{CV}$ risk factor, were assigned to either chlorthalidone $\quad 12.5-25 \mathrm{mg} / \mathrm{day}, \quad$ amlodipine $2.5-10 \mathrm{mg} / \mathrm{day}$, or lisinopril $10-40 \mathrm{mg} / \mathrm{day}$, and monitored for 4-8 years.

After 5-year follow-up, systolic BP was significantly higher in patients treated with amlodipine $(+0.8 \mathrm{mmHg}$; $\mathrm{p}=0.03)$ and lisinopril $(+2 \mathrm{mmHg} ; \mathrm{p}<0.001)$ compared with chlorthalidone, whereas diastolic BP was significantly lower with amlodipine $(-0.8 \mathrm{mmHg} ; \mathrm{p}<0.001)$. Despite these differences in BP, there were no between treatment group differences for the incidence of the primary composite endpoint (combined fatal coronary heart disease or nonfatal myocardial infarction), or for all-cause mortality [43].

An amlodipine-based regimen reduced the incidence of $\mathrm{CV}$ events and diabetes when compared with an atenololbased regimen in the Anglo-Scandinavian Cardiac Outcomes Trial-Blood Pressure Lowering Arm (ASCOTBPLA) trial [44]. ASCOT-BPLA was a prospective, multicenter, randomized, clinical trial, which enrolled 19,257 patients with hypertension and at least three other $\mathrm{CV}$ risk factors. Patients were randomized to either an amlodipinebased regimen (amlodipine 5-10 mg plus perindopril $4-8 \mathrm{mg}$ as required; $\mathrm{n}=9639$ ) or an atenolol-based regimen (atenolol 50-100 mg plus bendroflumethiazide $1.25-2.5 \mathrm{mg}$ and potassium as required; $\mathrm{n}=9618$ ). Patients treated with the amlodipine-based regimen had lower BP values during the follow-up period than those allocated to the atenolol-based regimen. As the trial was stopped prematurely, the primary endpoint of non-fatal myocardial infarction and fatal coronary heart disease did not reach significance [hazard ratio (HR) $0.90,95 \%$ confidence interval (CI) 0.79-1.02; $\mathrm{p}=0.1052$ ]. However, the amlodipine-based regimen significantly reduced the primary and secondary endpoints of all-cause mortality (by $11 \% ; \mathrm{p}=0.0247$ ), CV mortality (by $24 \% ; \mathrm{p}=0.0010$ ), total CV events and procedures (by $16 \% ; \mathrm{p}<0.0001$ ), total coronary endpoints (by 13\%; $\mathrm{p}=0.0070$ ), and fatal and non-fatal stroke (by 23\%; $\mathrm{p}=0.003$ ), compared with the atenolol-based regimen [44].

Benazepril plus amlodipine showed superior efficacy to benazepril plus hydrochlorothiazide in reducing $\mathrm{CV}$ events in 11,506 patients with hypertension at high CV risk in the Avoiding CV Events through Combination Therapy in Patients Living with Systolic Hypertension (ACCOMPLISH) trial [45]. In this trial, which was terminated early after exceeding the limit of the pre-specified stopping rule (mean follow-up of 36 months), combination therapy with benazepril plus amlodipine significantly reduced the incidence of both primary (HR $0.80,95 \%$ CI $0.72-0.90$; $\mathrm{p}<0.001$ ) and secondary (HR $0.79,95 \%$ CI $0.67-0.92$; $\mathrm{p}=0.002$ ) endpoints compared with combination therapy with benazepril plus hydrochlorothiazide [45].

\section{Clinical Efficacy and Tolerability of Barnidipine}

The antihypertensive efficacy, safety and tolerability profile of barnidipine has been evaluated in numerous clinical studies involving hypertensive patients with different $\mathrm{CV}$ risk profiles [47].

Similar antihypertensive efficacy of barnidipine $10 \mathrm{mg}$ and amlodipine 5-10 mg once daily was demonstrated in a 24-week, randomized, open-label, pilot study, which included 30 untreated patients (mean age 47 years) with grade 1-2 essential hypertension, as defined by an office sitting systolic BP of $140-179 \mathrm{mmHg}$ and diastolic BP of 90-109 mmHg [48]. Although the sample size was small, no significant differences in mean BP reductions were identified at study end for the barnidipine versus amlodipine treatment groups (office BP $-10.3 /-9.4$ versus $-16.6 /-9.1 \mathrm{mmHg}$; ambulatory BP 9.4/6.4 versus $8.1 / 5.1 \mathrm{mmHg}$ ) [48]. It should be noted, however, that the dose of amlodipine was doubled to $10 \mathrm{mg}$ in 6 patients due to inadequate BP control after 12 weeks' treatment, whereas drug dosage remained constant in the barnidipine group [48]. In addition, drug-related adverse events (including ankle oedema, headache, and palpitations) were significantly higher in the amlodipine group compared with barnidipine (60 versus $13 \%$; $p<0.05$ ) [48].

The BP-lowering effect of barnidipine $10-20 \mathrm{mg}$ in combination with losartan $50 \mathrm{mg}$ showed no significant differences when compared with losartan $100 \mathrm{mg}$ as monotherapy in 53 patients with grade 1-2 essential hypertension and uncontrolled BP following a 1-week runin period under losartan $50 \mathrm{mg}$ monotherapy [49]. However, a significantly higher percentage of responders for systolic BP was demonstrated with barnidipine plus losartan compared with losartan monotherapy (82.1 versus $56.0 \% ; \mathrm{p}=0.044$ ), and barnidipine plus losartan provided better and sustained antihypertensive efficacy over $24 \mathrm{~h}$, mostly during the last hours of the night-time period (Fig. 1) [49]. In this 12-week, multicenter, randomized, open-label, parallel-group study, the dosage of barnidipine was doubled to $20 \mathrm{mg}$ in patients with uncontrolled BP on combination therapy after 6 weeks of treatment, and patients were treated for a further 6 weeks, whereas patients on losartan $100 \mathrm{mg}$ who did not achieve BP control at 6 weeks were discontinued. The primary endpoint was the change in daytime diastolic BP between baseline and 12 weeks' treatment; tolerability, safety and adherence to prescribed medications were also assessed. In total, 18 patients with uncontrolled BP after 6 weeks' treatment with barnidipine plus losartan (64.3\%) had their dose of barnidipine doubled to $20 \mathrm{mg}$, and 8 patients in the losartan group $(32.0 \%)$ were discontinued. In general, both 
treatments were well tolerated and safe, with no significant differences between treatment groups [49].

The BArnidipine real-life Safety and tolerability In Chronic HyperTension (BASIC-HT) study, a large observational study which included a population sample of 20,479 adult outpatients with essential hypertension, assessed the effectiveness and tolerability of barnidipine in a setting of real-life practice in Belgium and Luxembourg [50]. Efficacy, safety and tolerability of antihypertensive therapies were assessed at two visits during a 3-month follow-up. This study showed that $40 \%$ of the patients received barnidipine as first-line therapy and a further $40 \%$ were administered barnidipine in combination with other antihypertensive drugs [50]. Notably, barnidipine, as monotherapy $(12 \%)$ or in combination with other antihypertensive drugs $(9 \%)$, replaced another antihypertensive therapy in $20 \%$ of the patients [50]. For patients previously treated with other CCBs, mostly including amlodipine or lercanidipine, the reason for switching to barnidipine-based therapy was mainly due to safety (42\%), lack of efficacy (28\%), or both $(11 \%)$. Reductions of systolic and diastolic BP levels during the observational period are reported in Fig. 2 [50]. Overall, the antihypertensive therapies were generally well tolerated and adverse events were reported for approximately $10 \%$ of patients, with a total drop-out rate of $8 \%$ after the 3-month follow-up period [50].

A subsequent analysis of the BASIC-HT database, which evaluated the efficacy and tolerability of barnidipine in a subgroup of patients for whom treatment with barnidipine replaced amlodipine or lercanidipine, suggested that replacement with barnidipine was a valuable therapeutic option, particularly when tolerability with other CCBs was an issue [51]. In total, 1710 patients with mild to moderate hypertension switched treatment from amlodipine or lercanidipine to barnidipine, either as monotherapy (approximately $51 \%$ of patients) or in combination with other antihypertensive drug classes (approximately $48 \%$ of patients) [51]. The decrease in systolic and diastolic BP levels during the observational period are reported in Fig. 3 [51]. The primary cause for switching treatment to barnidipine was related to at least one tolerability reason (peripheral oedema and headache) [51]. The main reason for switching treatment was tolerability. Indeed, 65.4\% (1094/ 1674 ) of patients previously treated with amlodipine or lercanidipine switched to barnidipine for at least one tolerability reason (tolerability alone or tolerability and other reason). Effectiveness was given as the reason for $41.6 \%$ (697/1674) of patients who switched to barnidipine (effectiveness alone or effectiveness and other reason) [51].

The occurrence of drug-related adverse events in switcher patients was relatively low (around 10\%) during the subsequent 3-month follow-up, and similar in frequency to the overall switcher population in BASIC-HT [50]. This analysis showed that that $37.1 \%$ (571/1539; $95 \%$ CI $34.7 \%$; 39.6\%) of the switchers achieved normalization of both SBP and DBP at the end of the 3-month follow-up period versus $9.4 \%[144 / 1539 ; 95 \%$ CI $8.0 \% ; 10.9 \%]$ at inclusion $(\mathrm{p}<0.0001)[51]$.

\section{Barnidipine and Organ Protection}

A number of clinical studies have also demonstrated the beneficial effects of barnidipine in terms of protection from hypertension-related organ damage.
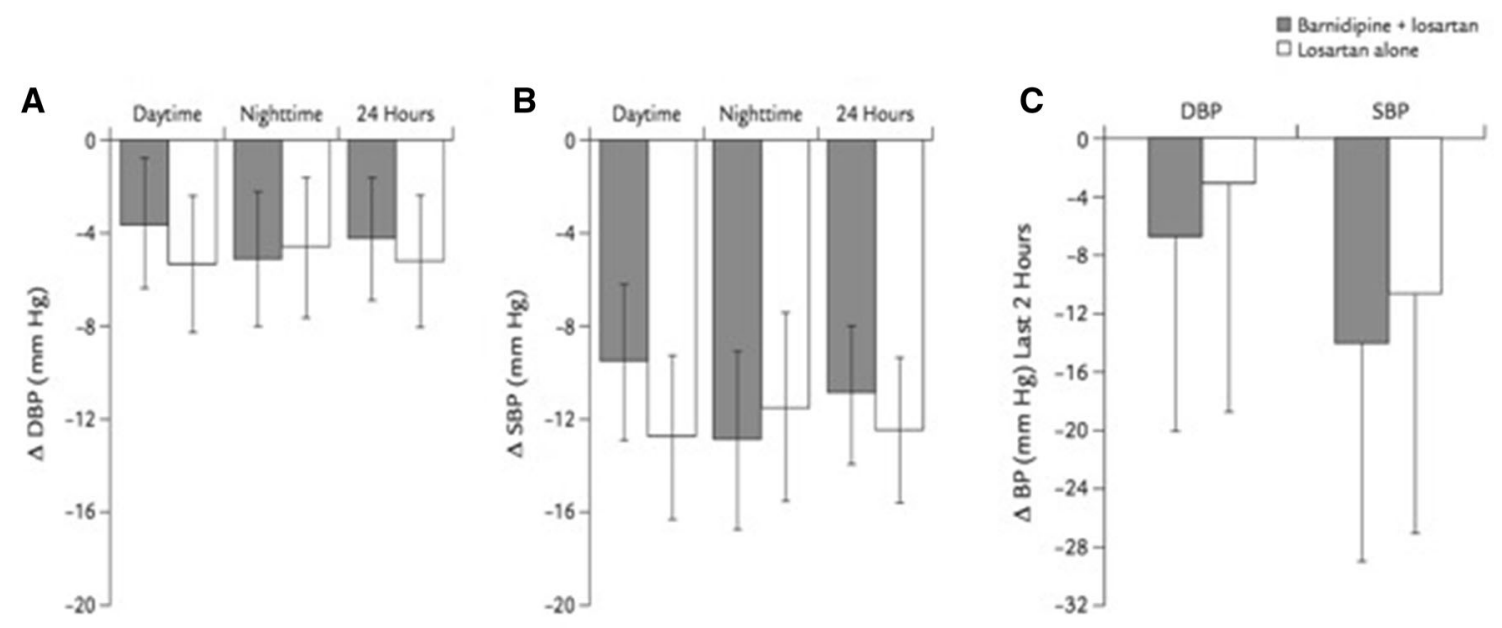

Fig. 1 Average changes in day-time, night-time, and 24-h diastolic (a) and systolic (b) blood pressure (BP) levels after 12 weeks of treatment with either combination therapy with barnidipine $10-20 \mathrm{mg}$ plus losartan $50 \mathrm{mg}(\mathrm{n}=28)$ or monotherapy with losartan $100 \mathrm{mg}$ $(\mathrm{n}=25)$. Changes in diastolic and systolic BP levels during the last $2 \mathrm{~h}$ of the dosing interval measured with 24-hour ambulatory BP monitoring) are shown in (c). Derived from reference num. [49]. In the figure: $S B P$ systolic blood pressure; $D B P$ diastolic blood pressure 

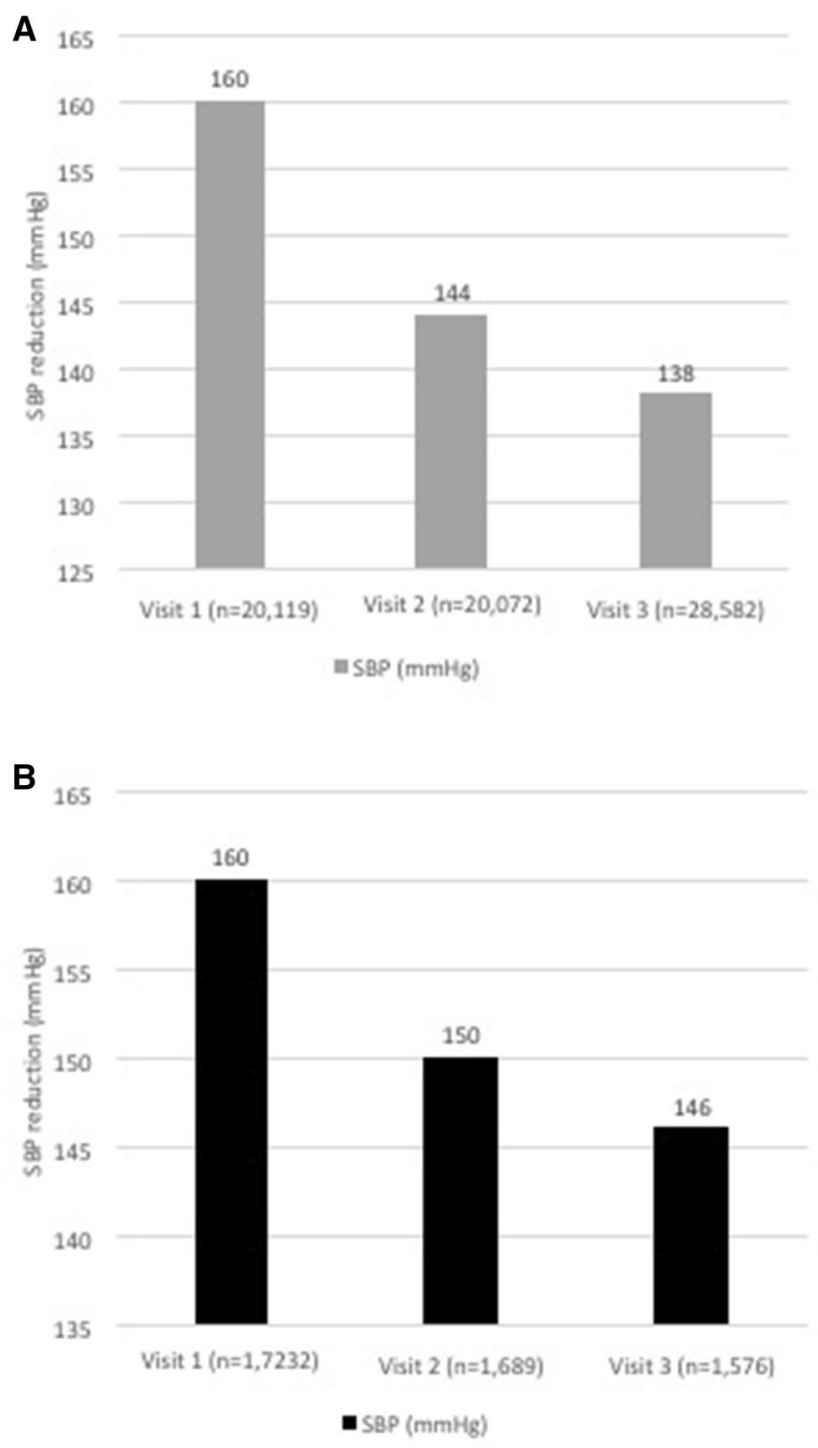

Fig. 2 Mean systolic and diastolic blood pressure reductions throughout the 3-month follow-up period in hypertensive patients treated with barnidipine as monotherapy, combination therapy or replacement therapy (a), or in hypertensive patients treated with

Favourable effects on markers of cardiac organ damage were demonstrated in a randomized, open-label, pilot study of 30 untreated patients with grade 1-2 essential hypertension who were treated with either barnidipine $10 \mathrm{mg}$ or amlodipine 5-10 mg once daily [48]. In this study, both barnidipine and amlodipine provided similar reductions of left ventricular mass, without significant differences between the two treatment arms. However, only barnidipine provided significant reduction of left ventricular mass compared with baseline values $(\mathrm{p}<0.05)$, which were also higher in barnidipina group compared to amlodipine group (Fig. 4) [48]. In addition, significantly more patients in the amlodipine group reported drug-related adverse events
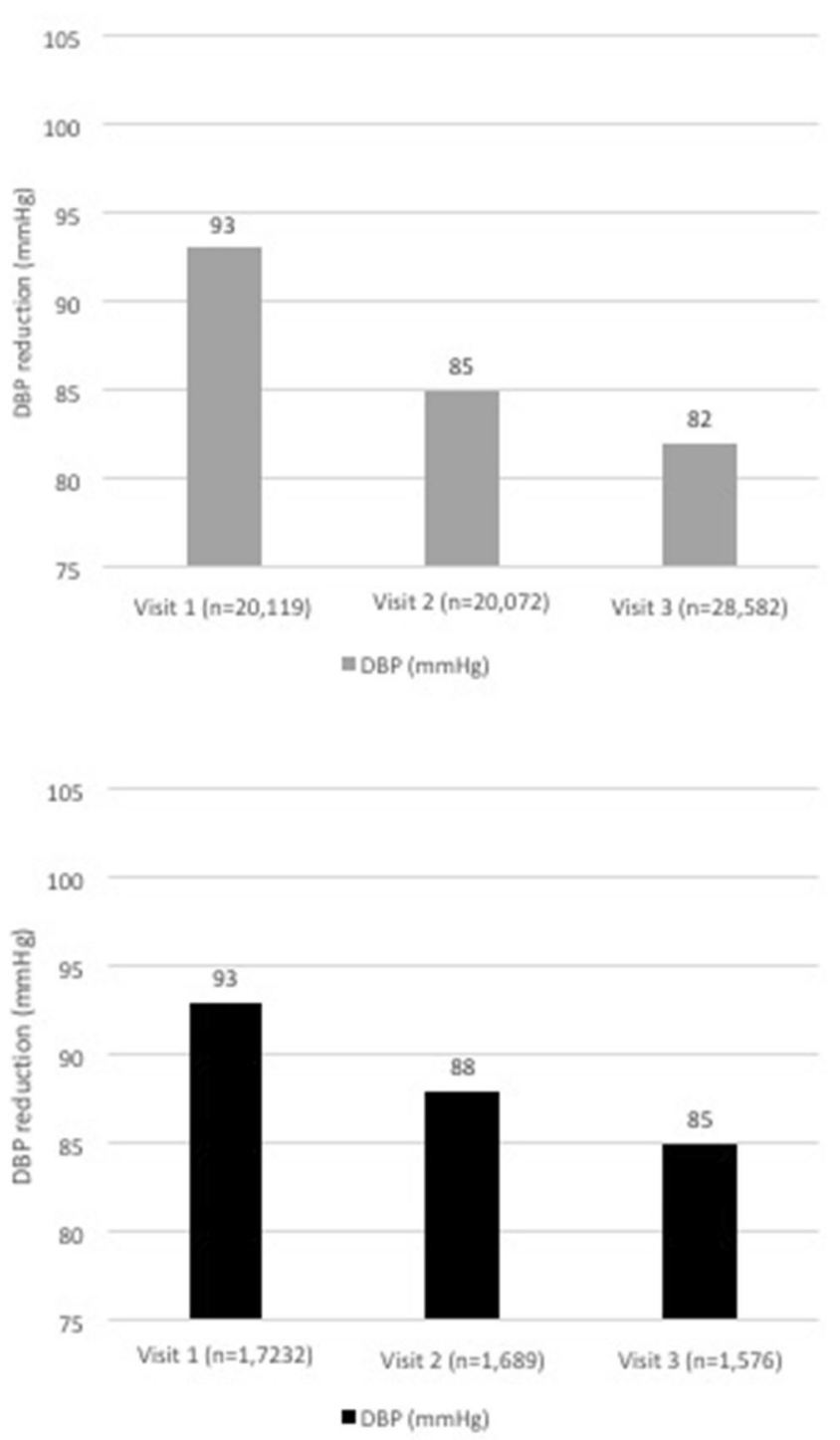

barnidipine after switching from other calcium channel blockers, mostly including amlodipine or lercanidipine (b). Derived from reference num. [50]. In the figure: $S B P$ systolic blood pressure; $D B P$ diastolic blood pressure

compared with those in the barnidipine group [9 (60\%) versus $2(13 \%) ; \mathrm{p}<0.05]$ [48].

Improvement in left ventricular diastolic relaxation, as assessed by tissue Doppler imaging (TDI) echocardiography, was shown following 12 weeks' treatment with barnidipine monotherapy $10-20 \mathrm{mg}$ once daily in 30 patients with grade 1-2 hypertension and metabolic syndrome who also underwent lifestyle changes [52]. At study end, mean office BP was $<140 / 90 \mathrm{mmHg}$ in 20 patients $(66.7 \%)$, with significant reductions in mean systolic and diastolic BP from baseline (both $\mathrm{p}=0.001$ ); significant reductions were also shown in 24-h ambulatory systolic and diastolic BP levels (both $p=0.001$ versus baseline). In addition, there was a significant decrease in fasting plasma 


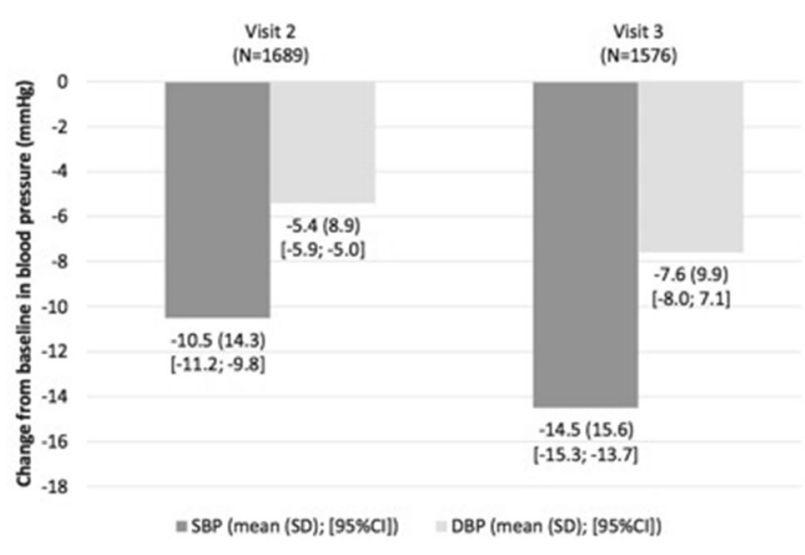

Fig. 3 Mean systolic and diastolic blood pressure reductions throughout the 3-month follow-up period hypertensive patients treated with barnidipine after switching from other calcium channel blockers, mostly including amlodipine or lercanidipine, at visit 2 and visit 3. Derived from reference num. [51]. In the figure: $S B P$ systolic blood pressure; $D B P$ diastolic blood pressure

glucose concentration at study end versus baseline (104 versus $110 \mathrm{mg} / \mathrm{dL} ; \mathrm{p}=0.001$ ), without relevant changes in lipid profiles [52]. No significant changes in left ventricular structure or systolic function were recorded, while the peak E/A velocity ratio on TDI was significantly increased from 1.078 at baseline to 1.245 at study end $(\mathrm{p}=0.009)$ [52]. No significant adverse events or drug-related reactions were observed during the observational period.

Greater improvement of echocardiographic parameters were shown for barnidipine plus losartan compared with lercanidipine plus losartan in a relatively small sample of hypertensive patients $(n=144)$ with diabetes and left ventricular hypertrophy [53]. In addition to losartan $100 \mathrm{mg} /$ day, patients were randomized to receive either

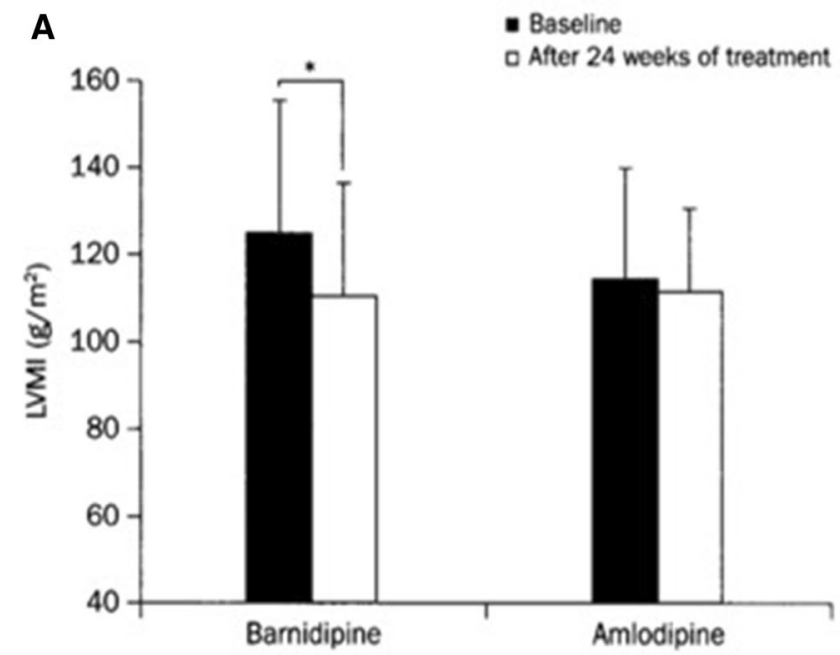

Fig. 4 Average left ventricular mass index at baseline of treatment (a) and corresponding baseline-adjusted mean changes after 24 weeks (b) in patients with essential hypertension randomized to treatment lercanidipine $20 \mathrm{mg} / \mathrm{day}$ or barnidipine $20 \mathrm{mg} / \mathrm{day}$ for 6 months. Both drug regimens reduced clinic BP levels at the end of the follow-up period, with no significant differences between treatment groups. However, a significant reduction in left ventricular mass index was identified in patients who received barnidipine plus losartan compared with lercanidipine plus losartan $(\mathrm{p}<0.05)$. Treatment with barnidipine plus losartan also increased the ratio of peak early diastolic filling velocity to peak filling velocity at atrial contraction $(\mathrm{p}<0.01$ versus baseline), but this was not increased by lercanidipine plus losartan, thus ameliorating diastolic function in these patients. In addition, isovolumetric relaxation and time and left atrial volume index were reduced in patients treated with barnidipine plus losartan, but not with lercanidipine plus losartan [53].

Treatment with barnidipine plus losartan improved parameters indicative of endothelial damage and oxidative stress in 151 patients with mild to moderate hypertension and type 2 diabetes mellitus randomized to receive either barnidipine $20 \mathrm{mg} / \mathrm{day}$, or lercanidipine $20 \mathrm{mg} / \mathrm{day}$, in addition to losartan $100 \mathrm{mg} / \mathrm{day}$, for 6 months [54]. Significant reductions in clinic and 24-h ambulatory BP were shown for both treatment groups at study end $(\mathrm{p}<0.001$ for barnidipine plus losartan and $\mathrm{p}<0.01$ for lercanidipine plus losartan, versus baseline), however, BP reduction was greater in patients treated with barnidipine plus losartan than those treated with lercanidipine plus losartan $(p<0.05)$ [54]. Levels of high-sensitivity C-reactive protein, tumor necrosis factor-alpha, soluble vascular adhesion protein-1, soluble intercellular adhesion protein-1, and isoprostanes were significantly reduced with barnidipine plus losartan the compared with both baseline and with lercanidipine plus losartan (all $\mathrm{p}<0.05$ ) [54].

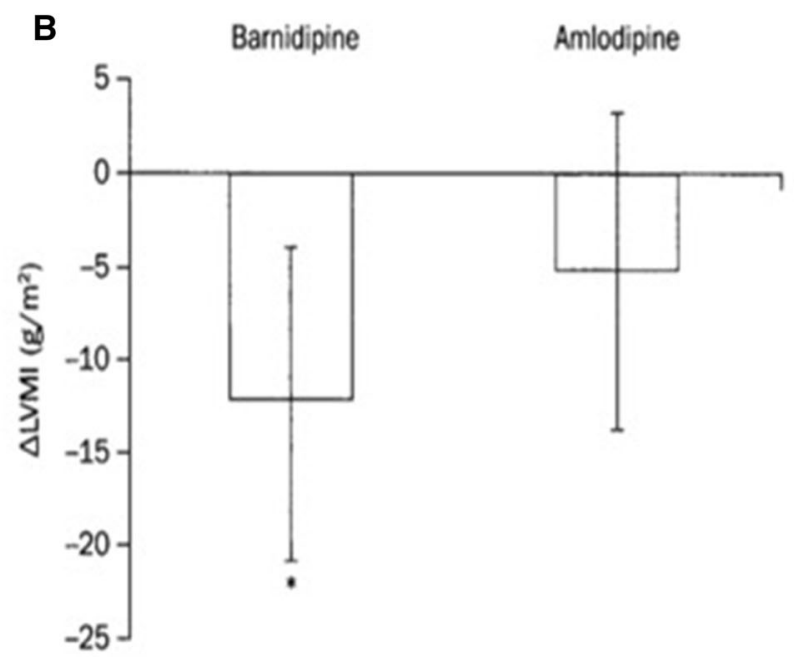

with either amlodipine or barnidipine. $* \mathrm{p}<0.05$ versus baseline. Derived from reference num. [48] In the figure: $L V M i$ left ventricular mass index 
Similar findings were also observed by Muiesan and coworkers, who suggested that barnidipine may have a favourable effect on endothelial dysfunction in patients with mild to moderate hypertension [55]. This study investigated the effect of barnidipine on endothelial function compared with hydrochlorothiazide, based on assessment by flow-mediated vasodilation of the brachial artery, in a cohort of 40 adult hypertensive outpatients. Clinic BP was significantly reduced in both treatment groups after 12 and 24 weeks of treatment, however, a significant reduction in 24-h systolic and diastolic BP was only observed in patients treated with barnidipine [55]. In addition, the percentage change of flow-mediated vasodilation was significantly improved at both 12 and 24 weeks in patients treated with barnidipine, but not in those treated with hydrochlorothiazide [55].

\section{Conclusion}

Treating hypertension still represents a difficult clinical task, due to the complexity of the disease and the frequent concomitant presence of associated CV risk factors and comorbidities, which render BP difficult to manage in hypertensive patients. Despite a reported substantial equivalence among antihypertensive drug classes, both in terms of antihypertensive efficacy and of CV protection, there are several differences that may have at least, in part, clinical relevance, such as sustained BP lowering effectiveness, tolerability, and protection from hypertensionrelated organ damage. CCBs have been demonstrated to be safe, effective and well-tolerated antihypertensive drugs in various clinical settings, including high-risk hypertensive patients, coronary artery disease, stroke, renal disease, and congestive heart failure. Among these drugs, barnidipine may represent an ideal option both as first line therapy and as combination therapy for antihypertensive strategies aimed at achieving the recommended BP targets, and providing protection from hypertension-related organ damage.

Acknowledgements Editorial assistance was provided by Dr Melanie Gatt $(\mathrm{PhD})$, an independent medical writer, on behalf of Springer Healthcare Communications. This assistance was funded with the unconditional support of Alfasigma.

\section{Compliance with Ethical Standards}

Funding Expert review of the manuscript has been founded by Alfasigma.

Conflict of interest Authors have no conflict of interest to disclose.

Ethical approval This article does not contain data derived by any current studies with human participants performed by any of the authors. The clinical studies mentioned were provided with specific ethical approval.

Open Access This article is distributed under the terms of the Creative Commons Attribution-NonCommercial 4.0 International License (http://creativecommons.org/licenses/by-nc/4.0/), which permits any noncommercial use, distribution, and reproduction in any medium, provided you give appropriate credit to the original author(s) and the source, provide a link to the Creative Commons license, and indicate if changes were made.

\section{References}

1. Bramlage P, Bohm M, Volpe M, Khan BV, Paar WD, Tebbe U, et al. A global perspective on blood pressure treatment and control in a referred cohort of hypertensive patients. J Clin Hypertens (Greenwich). 2010;12(9):666-77.

2. Borghi C, Tubach F, De Backer G, Dallongeville J, Guallar E, Medina $\mathrm{J}$, et al. Lack of control of hypertension in primary cardiovascular disease prevention in Europe: Results from the EURIKA study. Int J Cardiol. 2016;218:83-8.

3. Prugger C, Keil U, Wellmann J, de Bacquer D, de Backer G, Ambrosio GB, et al. Blood pressure control and knowledge of target blood pressure in coronary patients across Europe: results from the EUROASPIRE III survey. J Hypertens. 2011;29(8):1641-8.

4. Tocci G, Nati G, Cricelli C, Parretti D, Lapi F, Ferrucci A, et al. Prevalence and control of hypertension in the general practice in Italy: updated analysis of a large database. J Hum Hypertens. 2017;31(4):258-62.

5. Tocci G, Ferrucci A, Pontremoli R, Ferri C, Rosei EA, Morganti A, et al. Blood pressure levels and control in Italy: comprehensive analysis of clinical data from 2000-2005 and 2005-2011 hypertension surveys. J Hum Hypertens. 2015;29(11):696-701.

6. Olsen MH, Angell SY, Asma S, Boutouyrie P, Burger D, Chirinos JA, et al. A call to action and a lifecourse strategy to address the global burden of raised blood pressure on current and future generations: the Lancet Commission on hypertension. Lancet. 2016;388(10060):2665-712.

7. Volpe M, Erhardt LRW, Williams B. Cardiovascular risk management in clinical practice: time to change. High Blood Press Cardiovasc Prev. 2008;15(1):9-16.

8. Redon J, Mourad JJ, Schmieder RE, Volpe M, Weiss TW. Why in 2016 are patients with hypertension not $100 \%$ controlled? A call to action. J Hypertens. 2016;34(8):1480-8.

9. Mancia G, Fagard R, Narkiewicz K, Redon J, Zanchetti A, Bohm $\mathrm{M}$, et al. $2013 \mathrm{ESH} / \mathrm{ESC}$ Guidelines for the management of arterial hypertension: the Task Force for the management of arterial hypertension of the European Society of Hypertension (ESH) and of the European Society of Cardiology (ESC). J Hypertens. 2013;31(7):1281-357.

10. Volpe M, Rosei EA, Ambrosioni E, Cottone S, Cuspidi C, Borghi C, et al. 2012 consensus document of the Italian Society of Hypertension (SIIA): strategies to improve blood pressure control in Italy: from global cardiovascular risk stratification to combination therapy. High Blood Press Cardiovasc Prev. 2013;20(1):45-52.

11. Kates RE. Calcium antagonists. Pharmacokinetic properties. Drugs. 1983;25(2):113-24.

12. Zsoter TT, Church JG. Calcium antagonists. Pharmacodynamic effects and mechanism of action. Drugs. 1983;25(2):93-112.

13. Theroux P, Taeymans Y, Waters DD. Calcium antagonists. Clinical use in the treatment of angina. Drugs. 1983;25(2):178-95. 
14. Spivack C, Ocken S, Frishman WH. Calcium antagonists. Clinical use in the treatment of systemic hypertension. Drugs. 1983;25(2):154-77.

15. Singh BN, Nademanee K, Baky SH. Calcium antagonists. Clinical use in the treatment of arrhythmias. Drugs. 1983;25(2):125-53.

16. Toyo-Oka T, Nayler WG. Third generation calcium entry blockers. Blood Press. 1996;5(4):206-8.

17. Luscher TF, Cosentino F. The classification of calcium antagonists and their selection in the treatment of hypertension. A reappraisal. Drugs. 1998;55(4):509-17.

18. McKeage K, Scott LJ. Manidipine: a review of its use in the management of hypertension. Drugs. 2004;64(17):1923-40.

19. Cheer SM, McClellan K. Manidipine: a review of its use in hypertension. Drugs. 2001;61(12):1777-99.

20. Todd PA, Faulds D. Felodipine. A review of the pharmacology and therapeutic use of the extended release formulation in cardiovascular disorders. Drugs. 1992;44(2):251-77.

21. Saltiel E, Ellrodt AG, Monk JP, Langley MS. Felodipine. A review of its pharmacodynamic and pharmacokinetic properties, and therapeutic use in hypertension. Drugs. 1988;36(4):387-428.

22. Sorkin EM, Clissold SP. Nicardipine. A review of its pharmacodynamic and pharmacokinetic properties, and therapeutic efficacy, in the treatment of angina pectoris, hypertension and related cardiovascular disorders. Drugs. 1987;33(4):296-345.

23. Hall ST, Harding SM, Evans GL, Pellegatti M, Rizzini P. Clinical pharmacology of lacidipine. J Cardiovasc Pharmacol. 1991;17(Suppl 4):S9-13.

24. Epstein M. Lercanidipine: a novel dihydropyridine calciumchannel blocker. Heart Dis. 2001;3(6):398-407.

25. van Zwieten PA. Pharmacological profile of barnidipine: a single optical isomer dihydropyridine calcium antagonist. Blood Press Suppl. 1998;1:5-8.

26. Haria M, Wagstaff AJ. Amlodipine. A reappraisal of its pharmacological properties and therapeutic use in cardiovascular disease. Drugs. 1995;50(3):560-86.

27. Liau CS. Barnidipine: a new calcium channel blocker for hypertension treatment. Expert Rev Cardiovasc Ther. 2005;3(2):207-13.

28. Palombo C, Malshi E, Morizzo C, Rakebrandt F, Corretti V, Santini F, et al. Arterial wave reflection during antihypertensive therapy with barnidipine: a 6-month, open-label study using an integrated cardiovascular ultrasound approach in patients with newly diagnosed hypertension. Clin Ther. 2009;31(12):2873-85.

29. Mancia G, Fagard R, Narkiewicz K, Redon J, Zanchetti A, Bohm $\mathrm{M}$, et al. $2013 \mathrm{ESH} / \mathrm{ESC}$ guidelines for the management of arterial hypertension: the Task Force for the Management of Arterial Hypertension of the European Society of Hypertension (ESH) and of the European Society of Cardiology (ESC). Eur Heart J. 2013;34(28):2159-219.

30. Elley CR, Gupta AK, Webster R, Selak V, Jun M, Patel A, et al. The efficacy and tolerability of 'polypills': meta-analysis of randomised controlled trials. PLoS ONE. 2012;7(12):e52145.

31. Makani H, Bangalore S, Romero J, Htyte N, Berrios RS, Makwana $\mathrm{H}$, et al. Peripheral edema associated with calcium channel blockers: incidence and withdrawal rate-a meta-analysis of randomized trials. J Hypertens. 2011;29(7):1270-80.

32. Messerli FH, Grossman E, Leonetti G. Antihypertensive therapy and new onset diabetes. J Hypertens. 2004;22(10):1845-7.

33. Alderman MH. New onset diabetes during antihypertensive therapy. Am J Hypertens. 2008;21(5):493-9.

34. Tocci G, Paneni F, Palano F, Sciarretta S, Ferrucci A, Kurtz T, et al. Angiotensin-converting enzyme inhibitors, angiotensin II receptor blockers and diabetes: a meta-analysis of placebo-controlled clinical trials. Am J Hypertens. 2011;24(5):582-90.
35. Staessen JA, Fagard R, Thijs L, Celis H, Arabidze GG, Birkenhager WH, et al. Randomised double-blind comparison of placebo and active treatment for older patients with isolated systolic hypertension. The Systolic Hypertension in Europe (Syst-Eur) Trial Investigators. Lancet. 1997;350(9080):757-64.

36. Hansson L, Lindholm LH, Ekbom T, Dahlof B, Lanke J, Schersten B, et al. Randomised trial of old and new antihypertensive drugs in elderly patients: cardiovascular mortality and morbidity the Swedish Trial in Old Patients with Hypertension-2 study. Lancet. 1999;354(9192):1751-6.

37. Brown MJ, Palmer CR, Castaigne A, de Leeuw PW, Mancia G, Rosenthal $\mathrm{T}$, et al. Morbidity and mortality in patients randomised to double-blind treatment with a long-acting calciumchannel blocker or diuretic in the International Nifedipine GITS study: intervention as a Goal in Hypertension Treatment (INSIGHT). Lancet. 2000;356(9227):366-72.

38. Malacco E, Mancia G, Rappelli A, Menotti A, Zuccaro MS, Coppini A. Treatment of isolated systolic hypertension: the SHELL study results. Blood Press. 2003;12(3):160-7.

39. Hansson L, Hedner T, Lund-Johansen P, Kjeldsen SE, Lindholm LH, Syvertsen JO, et al. Randomised trial of effects of calcium antagonists compared with diuretics and beta-blockers on cardiovascular morbidity and mortality in hypertension: the Nordic Diltiazem (NORDIL) study. Lancet. 2000;356(9227):359-65.

40. Black HR, Elliott WJ, Grandits G, Grambsch P, Lucente T, White WB, et al. Principal results of the Controlled Onset Verapamil Investigation of Cardiovascular End Points (CONVINCE) trial. JAMA. 2003;289(16):2073-82.

41. Pepine CJ, Handberg EM, Cooper-DeHoff RM, Marks RG, Kowey P, Messerli FH, et al. A calcium antagonist vs a noncalcium antagonist hypertension treatment strategy for patients with coronary artery disease. The International Verapamil-Trandolapril Study (INVEST): a randomized controlled trial. JAMA. 2003;290(21):2805-16.

42. Mancia G, Laurent S, Agabiti-Rosei E, Ambrosioni E, Burnier M, Caulfield MJ, et al. Reappraisal of European guidelines on hypertension management: a European Society of Hypertension Task Force document. Blood Press. 2009;18(6):308-47.

43. ALLHAT Officers and Coordinators for the ALLHAT Collaborative. Research Group. The Antihypertensive and Lipid-Lowering Treatment to Prevent Heart Attack Trial. Major outcomes in high-risk hypertensive patients randomized to angiotensin-converting enzyme inhibitor or calcium channel blocker vs diuretic: the Antihypertensive and Lipid-Lowering Treatment to Prevent Heart Attack Trial (ALLHAT). JAMA. 2002;288(23):2981-97.

44. Dahlof B, Sever PS, Poulter NR, Wedel H, Beevers DG, Caulfield $\mathrm{M}$, et al. Prevention of cardiovascular events with an antihypertensive regimen of amlodipine adding perindopril as required versus atenolol adding bendroflumethiazide as required, in the Anglo-Scandinavian Cardiac Outcomes Trial-Blood Pressure Lowering Arm (ASCOT-BPLA): a multicentre randomised controlled trial. Lancet. 2005;366(9489):895-906.

45. Jamerson K, Weber MA, Bakris GL, Dahlof B, Pitt B, Shi V, et al. Benazepril plus amlodipine or hydrochlorothiazide for hypertension in high-risk patients. $N$ Engl $J$ Med. 2008;359(23):2417-28.

46. Liu L, Zhang Y, Liu G, Li W, Zhang X, Zanchetti A. The Felodipine Event Reduction (FEVER) Study: a randomized longterm placebo-controlled trial in Chinese hypertensive patients. J Hypertens. 2005;23(12):2157-72.

47. Argenziano L, Izzo R, Iovino G, De Luca N, Parrella L, Morisco $\mathrm{C}$, et al. Distinct vasodilation, without reflex neurohormonal activation, induced by barnidipine in hypertensive patients. Blood Press Suppl. 1998;1:9-14.

48. Rossetti G, Pizzocri S, Brasca F, Pozzi M, Beltrami LM, Bolla $\mathrm{GB}$, et al. Antihypertensive effect of barnidipine $10 \mathrm{mg}$ or 
amlodipine 5 to $10 \mathrm{mg}$ once daily in treatment-naive patients with essential hypertension: a 24-week, randomized, open-label, pilot study. Curr Ther Res Clin Exp. 2008;69(3):192-206.

49. Parati G, Giglio A, Lonati L, Destro M, Ricci AR, Cagnoni F, et al. Effectiveness of barnidipine 10 or $20 \mathrm{mg}$ plus losartan 50-mg combination versus losartan 100-mg monotherapy in patients with essential hypertension not controlled by losartan 50-mg monotherapy: a 12-week, multicenter, randomized, openlabel, parallel-group study. Clin Ther. 2010;32(7):1270-84.

50. Lins R, Marckx P, Vandebeek R, Vanhoutvinck C, Neuville O. Barnidipine real-life tolerability in arterial hypertension: results from the BASIC-HT study. Acta Clin Belg. 2015;70(4):244-50.

51. Lins R, Haerden Y, de Vries C. Replacement of amlodipine and lercanidipine by barnidipine: tolerability and effectiveness in a real-life study. High Blood Press Cardiovasc Prev. 2017;24(1):29-36.

52. Angeli F, Repaci S, Borgioni C, Sardone M, Scotti A, Verdecchia P. Effects of barnidipine on blood pressure and left ventricular diastolic function in patients with hypertension and metabolic syndrome: a 12-week, open-label noncomparison study. Curr Ther Res Clin Exp. 2008;69(3):207-20.

53. Derosa G, Mugellini A, Querci F, Franzetti I, Pesce RM, D'Angelo A, et al. Barnidipine or lercanidipine on echocardiographic parameters in hypertensive, type 2 diabetics with left ventricular hypertrophy: a randomized clinical trial. Sci Rep. 2015;5:12603.

54. Derosa G, Mugellini A, Pesce RM, D'Angelo A, Maffioli P. Barnidipine compared to lercanidipine in addition to losartan on endothelial damage and oxidative stress parameters in patients with hypertension and type 2 diabetes mellitus. BMC Cardiovasc Disord. 2016;16:66.

55. Muiesan ML, Salvetti M, Belotti E, Paini A, Rosei CA, Aggiusti $\mathrm{C}$, et al. Effects of barnidipine in comparison with hydrochlorothiazide on endothelial function, as assessed by flow mediated vasodilatation in hypertensive patients. Blood Press. 2011;20(4):244-51. 